\title{
Inferring changes in North Sea benthos from fish stomach analysis
}

\author{
C. L. J. Frid ${ }^{1, *}$, S. J. Hall ${ }^{2}$ \\ ${ }^{1}$ Dove Marine Laboratory, University of Newcastle upon Tyne, Cullercoats, North Shields, \\ Tyne and Wear NE30 4PZ, United Kingdom \\ ${ }^{2}$ School of Biological Sciences, Faculty of Science \& Engineering, The Flinders University of South Australia, \\ GPO Box 2100, Adelaide 5001, South Australia, Australia
}

\begin{abstract}
In this study we formulated a prion hypotheses for the changes in the benthos that would be expected as a result of the direct impacts of trawl fisheries. These were tested using a data set comprising stomach contents for dab Limanda limanda collected in March and August in the early 1950 s and a matched sample from 1996-97. Changes in samples taken in August were consistent with the hypothesised effects of fishing, with an increased prevalence of scavengers and decreased occurrence of sedentary polychaetes in the diet. There were also marked differences between the 1950s and 1996-97 for March samples due to the high prevalence of fish remains in the contemporary samples. While our results must be treated with caution, they are consistent with the hypothesis that there have been widespread long term changes in benthic communities due to fishing.
\end{abstract}

KEY WORDS: Dab · Stomach contents $\cdot$ Benthos $\cdot$ Fishing disturbance $\cdot$ North Sea

\section{INTRODUCTION}

A continuing problem in assessing the impact of fishing on marine benthic communities is the lack of timeseries data for benthic populations. Since we cannot go back and collect more samples we are faced with searching for historical data sets from which comparisons can be made with the present situation. To date, most such efforts have involved re-analysis of infaunal and epifaunal benthic samples (e.g. Kröncke 1990, de Groot \& Lindeboom 1994). However, fish stomach contents provide another source of data that has hitherto been ignored - like grabs and dredges, benthic feeding fish sample the benthos. Although stomach samples are undoubtedly biased, trends in diet over time might nevertheless be expected to reflect food availability and allow inferences to be made about changes in the composition of the benthic community (Knust 1986, 1996).

Many authors (e.g. Creutzberg \& Duineveld 1986, deClerke \& Torreele 1988, Hall et al. 1990, Greenstreet

•E-mail: c.l.frid@ncl.ac.uk
1996) have described the consumption of benthic macrofaunal species by the dab Limanda limanda L. Since fish stomach contents have been closely correlated with benthic infaunal population densities (Knust 1986), it seems reasonable that historic fish stomach contents data may be compared against contemporary data to establish whether there have been any changes in the benthos of North Sea fishing grounds. In this paper we examine stomach contents data collected from dab in the 1950 s and compare this with contemporary (1996-97) samples collected from the same location and in the same seasons.

\section{MATERIAL AND METHODS}

Between July 1951 and July 1953, 73 otter trawl hauls were taken during daylight at 5 stations on Smith's Bank, Moray Firth (Fig. 1), by the research vessels RV 'Scotia' and RV 'Explorer' (Table 1). Details of the composition of the catch by fish species, the size of fish and, from laboratory analysis, their stomach contents (wet weight of prey by taxa) were recorded. 


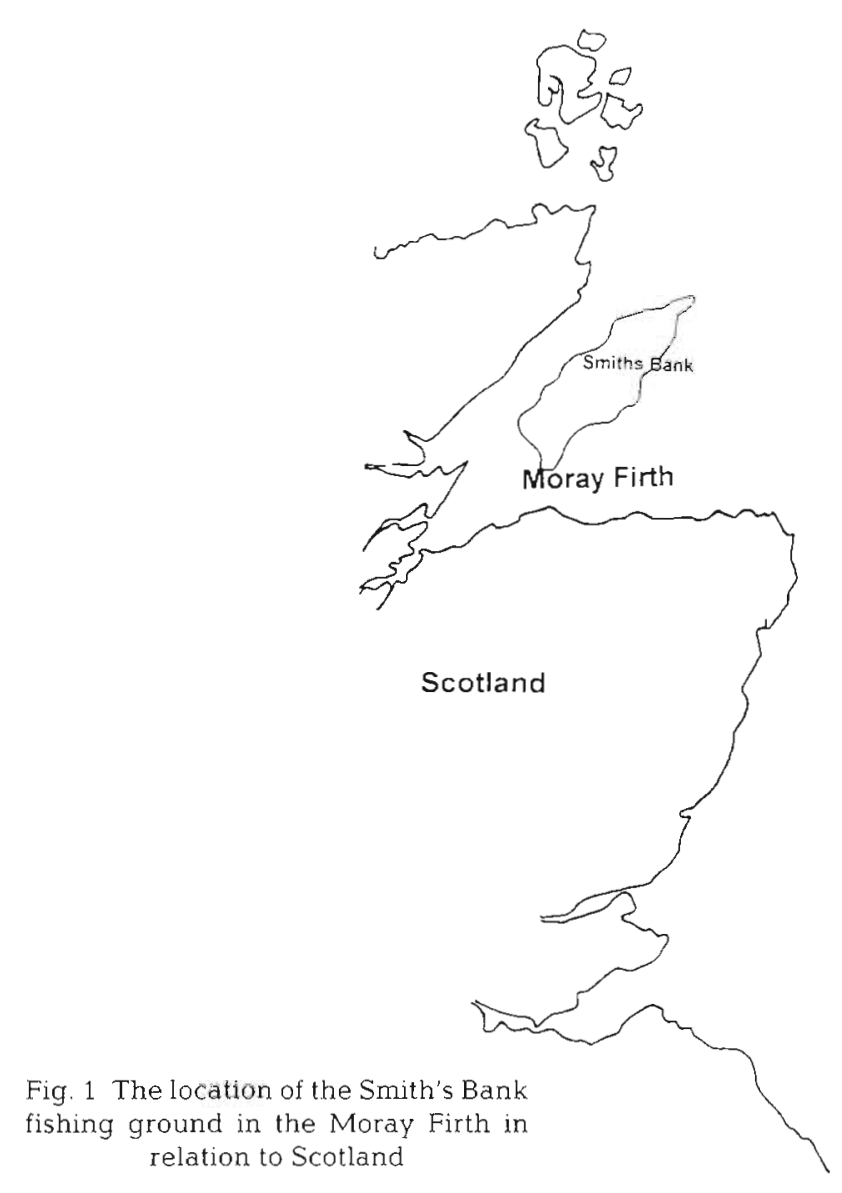

These data were archived at the Fisheries Research Laboratory, Aberdeen, and a preliminary analysis was undertaken to determine the optimal strategy for obtaining a matched contemporary sample, given practical constraints on ship time.

As more fish containing food were caught in hauls taken in March and August than in any other months and as stomach contents differed markedly between these times of year, contemporary samples were obtained during daylight in August 1996 and March 1997. A size matched sample of fish was used to limit biases associated with ontogenetic changes in feeding preferences. Contemporary samples were obtained, at sea, from the catch of the commercial fishing vessel, FV 'Transcend', on 12 August 1996 and 9 March 1997. On each occasion the sample was obtained from the catch of 2 hauls of a Danish seine, made in the midst of the original 5 stations. Dab were immediately frozen to prevent further digestion of prey. On return to the laboratory, fish were measured and the stomachs dissected. Similar proportions of stomachs containing at least 1 prey item were found in both periods (Table 2). All prey items were identified to the lowest possible taxon, blotted dry and weighed.

Statistical analysis. Our objective was to compare the diets of fish caught in the 1950 s with those caught in 1996-97. To examine differences in individual prey taxa, we calculated the percentage of (non-empty) stomachs in which a particular prey item occurred $(\%$ occurrence). The variability in these estimates was then determined by bootstrapping (Efron \& Tibshirani 1986). Given the relatively small sample sizes we chose percent occurrence, calculated from presence/absence data as the measure least likely to be influenced by the presence of a large number or biomass of prey in a small number of stomachs. The advantages of using a bootstrap technique to obtain confidence intervals for fish stomach data, compared to the delta (e.g. Bishop et al. 1975) or jack knife (Miller 1974) method are given in Hall et al. (1990). Bias corrected 95\% confidence intervals based on 1000 simulations were used throughout.

Before undertaking any statistical analysis, we placed all prey taxa found in the stomachs into 1 of 3 categories: taxa expected to increase under fishing (e.g. scavenging species such as decapod crustaceans and carnivorous gastropods), taxa expected to decrease (e.g. large bivalves, sedentary tube building polychaetes) and taxa for which no a priori predictions could be made. The latter include multi-taxa prey categories in which some taxa would show a positive response while others would decline. The membership of these categories and the justification for their inclusion is given in Table 3. By placing taxa into such categories we, in effect, set up a priori hypotheses for the changes we expect to see in stomach contents if fishing has affected benthic communities. These hypotheses are based in large part on intuition and previous analy-

Table 1. Size distribution of fish in the original samples from the Smith's Bank in March and August $1951-52$ and the number obtained as a matched sample in 1996-97

\begin{tabular}{|c|c|c|c|c|}
\hline \multirow[t]{2}{*}{ Size $(\mathrm{cm})$} & \multicolumn{2}{|c|}{ March } & \multicolumn{2}{|c|}{ August } \\
\hline & $\begin{array}{c}\text { Number in } \\
\text { original sample }\end{array}$ & $\begin{array}{l}\text { Number obtained for } \\
\text { matched sample }\end{array}$ & $\begin{array}{l}\text { Number in } \\
\text { original sample }\end{array}$ & $\begin{array}{c}\text { Number obtained for } \\
\text { matched sample }\end{array}$ \\
\hline $16-20$ & 146 & 94 & 82 & 100 \\
\hline $21-30$ & 94 & 74 & 53 & 100 \\
\hline $31-50$ & 6 & 2 & 5 & 1 \\
\hline
\end{tabular}


ses of the effects of trawling (de Groot \& Lindeboom 1994, Jennings \& Kaiser 1997, Thrush et al. 1998, Tuck et al. 1998). In addition to classifying prey taxa at the lowest practical taxonomic level, we also aggregated data to provide estimates of change for crustaceans, annelids, molluscs, echinoderms, fish and others. Finally, we examined the diet hrearth of fish in each season and time strata, using Levin's measure (Krebs 1989).

\section{RESULTS}

At first sight it might appear that changes in diet for samples taken in March support our hypotheses for species predicted to decline under fishing and contradict those predicted to increase (Fig. 2a,e). Unfortunately, however, the March samples for the later period were dominated by a very high occurrence of fish remains in the diet (Fig. 2c). Ironically, since our contemporary samples were only from 2 hauls, this high occurrence of fish is likely to be the result of feeding on discards, and we suspect that dabs with an opportunity to feed on discarded fish neglected other benthic prey taxa (see 'Discussion'). Thus, the high proportion of stomachs containing fish remains resulted in decreases in the occurrence of all other prey groups, many of them significant (Fig 2a,c,e). With regard to our primary objective, therefore, we conclude that the March samples provide no useful information.

The confidence intervals around the mean percentage occurrence of each prey type for August show a significant change over time for 4 of the prey types for which we predicted a directional change (Fig. 2b,f). For 3 of the 4 types the direction of the change were as we predicted (mollusc siphons and sedentary polychaetes decreased in the diet, while ophioroids increased). A further 2 prey types (crus-

Table 2. Limanda Limanda. Proportion of dabs from Smith's Bank with prey in their stomachs in the 1950 s and 1990 s

\begin{tabular}{|ccc|}
\hline & $1951-1952$ & $1996-1997$ \\
\hline Mar & $83 \%$ & $73 \%$ \\
Aug & $79 \%$ & $86 \%$ \\
\hline
\end{tabular}

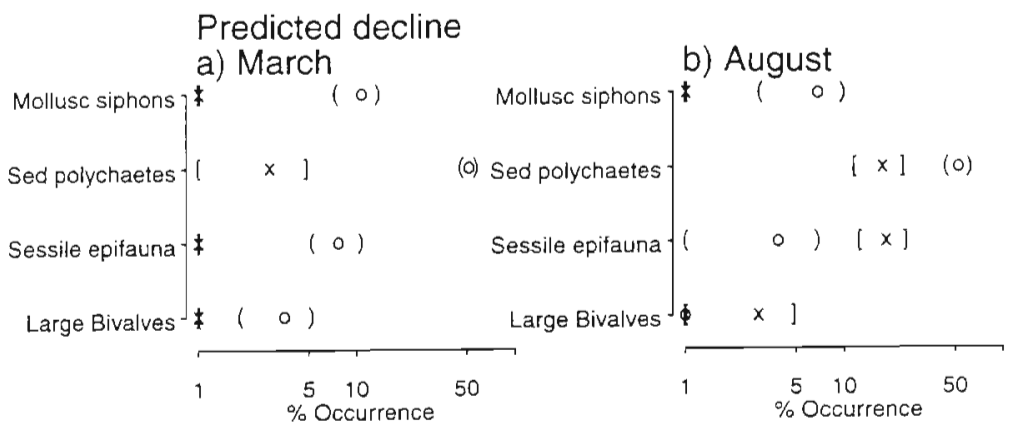

No prediction c) March

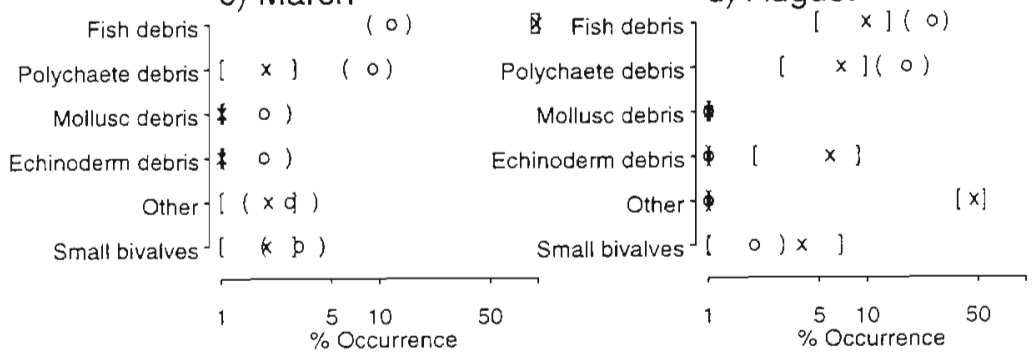

Predicted increase

e) March

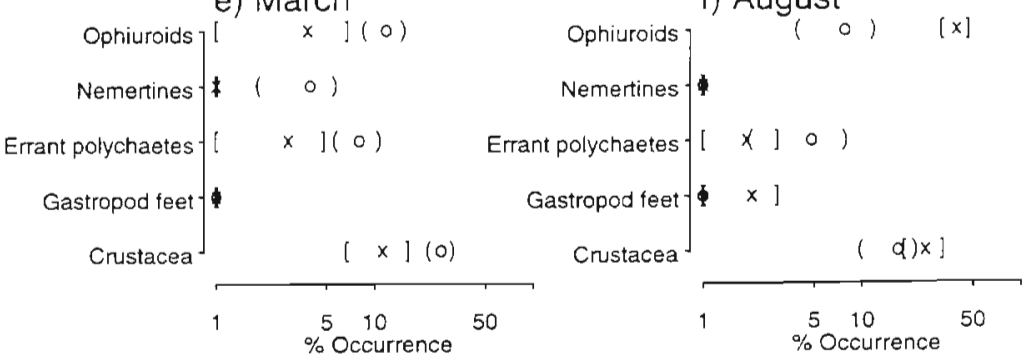

Fig. 2. Mean (0 1950s; $\times 1990 \mathrm{~s}$ ) and bootstrapped $95 \%$ confidence intervals, derived from 1000 randomizations, for the occurrence of various prey types in dab stomachs from March and August in 1951-52 and 1996-97. Prey types sorted a priori on the basis of their likelihood to increase or decrease as a result of fishing impacts. Details of rationale and composition of prey types are given in Table 3

taceans and gastropod feet) also showed changes in the direction predicted, but not significantly so. The only prey group showing a significant change that was opposite to our expectation was the poly-phyletic 'sessile epifauna' which was comprised primarily of hydroids and tunicates. Both these taxa contain species capable of rapid, asexual, colony growth over short time periods in summer leading to opportunistic dominance in areas of stable substratum. Of those prey groups for which directional predictions could not be made, we found equal numbers of significant increases and decreases (Fig. 2c,d).

While considerable care was taken to aggregate prey taxa into meaningful and robust prey categories, such aggregation might be seen as subjective. The 
Table 3. Categorisation of recorded prey classes into groups for which a priori hypotheses could be formulated for their response to fishing effects. The rationale is also given

\begin{tabular}{|c|c|c|c|}
\hline Prey category & $\begin{array}{l}\text { Predicted change } \\
\text { due to fishing }\end{array}$ & Rationale & Prey classes contributing \\
\hline Large bivalves & Decline & Slow growing, relatively fragile & Arctica, Chlamys, Mactra \\
\hline Sessile epifauna & Decline & Surface dwelling, often erect growth form. & Hydroids, bryozoans, tunicates \\
\hline Sedentary polychaetes & Decline & Tube building, large sessile forms & $\begin{array}{l}\text { All sedentary polychaete taxa } \\
\text { except Hydroides and terreblids } \\
\text { and sedentary polychaete debris }\end{array}$ \\
\hline Mollusc siphons & Decline & $\begin{array}{l}\text { Product of primarily slow growing, } \\
\text { relatively fragile forms }\end{array}$ & Bivalve siphons \\
\hline Small bivalves & No prediction & Variable group & Abra, Tellina and bivalve debris \\
\hline Other & No prediction & Variable group & $\begin{array}{l}\text { Hydroides norvegica, Crangon, } \\
\text { Terrebellids, Pennatulids and } \\
\text { unidentifiable remains }\end{array}$ \\
\hline Echinoderm debris & No prediction & $\begin{array}{l}\text { Variable group, including } \\
\text { non-attributable remains }\end{array}$ & \\
\hline Mollusc debris & No prediction & $\begin{array}{l}\text { Variable group, including } \\
\text { non-attributable remains }\end{array}$ & \\
\hline Polychaete debris & No prediction & $\begin{array}{l}\text { Variable group, including } \\
\text { non-attributable remains }\end{array}$ & $\begin{array}{l}\text { Polychaete debris not identifiable } \\
\text { to class }\end{array}$ \\
\hline Fish and fish debris & No prediction & $\begin{array}{l}\text { Variable group, including } \\
\text { non-attributable remains }\end{array}$ & All fish taxa and fish remains \\
\hline Crustacean scavengers & Increase & $\begin{array}{l}\text { Benefit from carrion generated by } \\
\text { trawls and discards }\end{array}$ & $\begin{array}{l}\text { Hermit crabs, crabs, isopods, and } \\
\text { amphipods }\end{array}$ \\
\hline Gastropod feet & Increase & $\begin{array}{l}\text { Neogastropods benefit from carrion } \\
\text { generated by trawls and discards }\end{array}$ & \\
\hline Errant polychaetes & Increase & $\begin{array}{l}\text { Benefit from disturbed sediments and organic } \\
\text { matter generated by trawls and discards }\end{array}$ & $\begin{array}{l}\text { All errant polychaete taxa and } \\
\text { errant polychaete debris }\end{array}$ \\
\hline Nemertines & Increase & $\begin{array}{l}\text { Benefit from disturbed sediments and organic } \\
\text { matter generated by trawls and discards }\end{array}$ & \\
\hline Ophioroids & Increase & $\begin{array}{l}\text { Benefit from disturbed sediments and organic } \\
\text { matter generated by trawls and discards }\end{array}$ & All ophioroid remains \\
\hline
\end{tabular}

same analysis was therefore carried out with the data aggregated at the phylum level. As before, the high occurrence of fish remains in the contemporary sample dominates the changes over time for the March comparison, resulting in significant decreases in the frequency of occurrence of all other prey classes (Fig. 3a). In contrast, for the August samples we found 2 groups which increased significantly over the time period (echinoderms and 'other' remains) and 2 (polychaetes and fish) which decreased significantly. Crustacean occurrences increased but not significantly.

Levin's diet breadth statistic varied significantly between time periods for both March and August (Fig. 4). In March the diet breadth was significantly narrower in the 1990s as a result of the dominance of fish remains in the sampled stomachs mentioned above. In contrast, for the August samples, in spite of the relatively high occurrence of hydroid remains, the diet was significantly broader in the 1990s than the 1950s. This result partly reflects the lower number of prey types found in the earlier time period ( 9 vs 12) but it is also a reflection of a more equitable percentage occurrence of the prey that were recorded in the diet. a) March

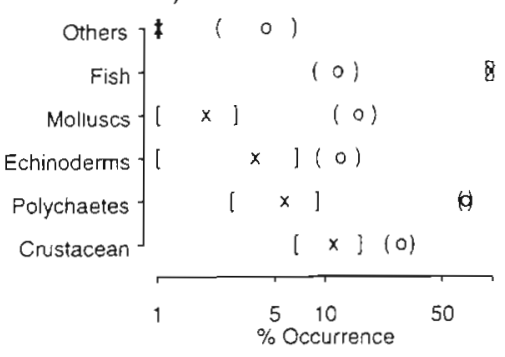

b) August

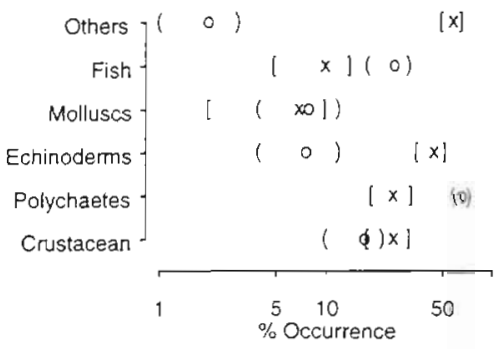

Fig. 3. Mean (0 1950s; $\times 1990 \mathrm{~s})$ and bootstrapped $95 \%$ confidence intervals, derived from 1000 randomizations, for the occurrence of various prey phyla in dab stomachs from (a) March and (b) August in 1951-52 and 1996-97 


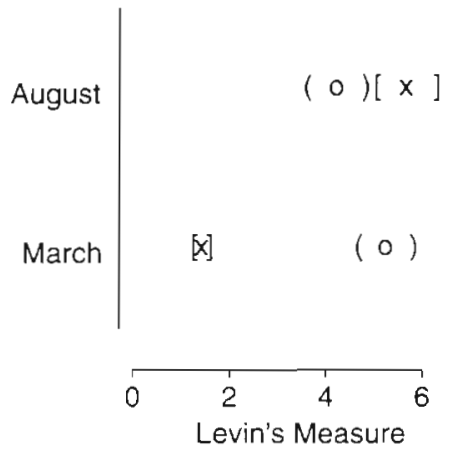

Fig. 4. Mean (o 1950s; $\times 1990$ s) and bootstrapped $95 \%$ conficence intervals, derived from 1000 randomizations, for the Levin's measure of diet breadth for dabs from March and August 1951-52 and 1996-97

\section{DISCUSSION}

This study set out to examine whether changes in the diet of dabs were consistent with a priori expectations concerning the effect of fishing on the benthos. With respect to our hypotheses, we found that, with one exception, the observed changes at the finest taxonomic resolution we employed were consistent with a fishing effect. The exception was a poly-phyletic group of fast growing opportunistic taxa, which can be seasonally dominant and tend to show greater inter-annual variability in summer samples, following recruitment, compared to samples taken in spring. At the phylum level changes in echinoderms, polychaetes and crustaceans were all in the direction predicted. Both crustacean and echinoderm prey comprised largely scavenging species and these increased, whereas the predominantly sedentary polychaete group decreased. Taken overall, we found dietary changes in August samples that were surprisingly consistent with a fisheries effect. It is with some irony, however, that the clearest difference between the 2 time periods was for March samples, resulting from changes in frequency of fish remains in the diet. While small fish are part of the 'normal diet' of dab (e.g. the 1950s data and Knust 1986, 1996) feeding on fishery discards is also a well-documented feature of their behaviour (Kaiser \& Spencer 1996). As our samples were taken on a fishing ground, we suspect that this may be the reason for the unusually high occurrence of fish in the diet. With respect to diet breadth, both the range of prey and the equability of occurrence have increased, suggesting that the benthic community has become more diverse with respect to available prey resources for dabs

Documented evidence of human effects on marine ecosystems tend to be limited to impacts that are small in their spatial extent, often arising from recognised point sources (Clark et al. 1997). The provision of robust scientific data that might help us to understand changes occurring over large spatial and temporal scales has been hampered by the methodological problems arising from sampling a naturally variable system. Comparisons over longer time frames are particularly difficult owing to the limited availability of suitable historic data. In this study we have utilised a set of data originally collected for studies on flatfish feeding behaviour to try and gain additional insights into changes in a benthic community. Although using data for purposes other than that for which it was originally intended is fraught with difficulties, we have tried to be pragmatic and overcome these with our approach to data collection and analysis. Nevertheless, problems with interpretation remain and a number of issues need to be addressed.

Perhaps the major concern relates to the relatively small sample sizes that were used. For the 1950 s data, we were forced to accept what was available, but for the contemporary data it would have been highly desirable to obtain a much larger number of samples. However, the practical constraint of available ship time meant that we could only collect a sample of comparable size to that in the earlier data set (approx. 100 stomachs for each season and time period). We believe we have used conservative criteria for examining trends, using bootstrapping as a robust technique for determining the statistical significance of any observed change. Although the number of stomachs used was comparable, the number of hauls from which they were obtained was greater in the 1950s. Dab are not a schooling fish, but if fish from a single haul were exploiting a particular prey patch the variability of the diet composition estimates would increase with increasing numbers of hauls. The lack of consistently wider confidence intervals for the 1950s estimates of prey abundance (Fig. 2) reassures us that this was not a problem with our analyses.

Other long term studies of North Sea benthos have tended to show increases in taxa with small body forms, particularly polychaetes (Reise 1982, Kröncke 1990). Such changes have often been attributed to eutrophication (e.g. Hickel et al. 1993, Josefson et al. 1993) and climatic processes (Pearson \& Mannvik 1998). However, these could also, at least in part, be due to the direct effects of fishing as many of the predictions for the effects of fishing and eutrophication are the same. In this study we have argued that observed changes in stomach contents match the predictions of the fishing effect, but clearly many of these responses might be the result of other impacts, or natural variation. However, the reduction in the occurrence of sedentary forms, which are likely to be especially sensitive to physical impacts, does seem to be more consistent with a fishing effect than anything else. 
The adoption of a precautionary approach to ecosystem management has lead to increasing concern over possible effects of anthropogenic impacts occurring over larger spatial scales and longer time period. This presents a major challenge to scientists in terms of gathering information and providing advice in the face of large uncertainties. If science is to play a role in ecosystem management it must be willing to utilise all available data, accepting that this will often fall short of the ideal in terms of the assumptions that need to be made. While we would not claim that our analysis of fish stomachs is by any means definitive, the trends observed are striking and worthy of comment. They must be viewed, however, with considerable circumspection. Based on one of the few available data sets, we have shown evidence for changes in fish diets consistent with an effect of fishing activities. It remains to be seen whether other data sets can be unearthed which are also consistent with such hypotheses. The existence of such changes would imply that ecosystem considerations need to be explicitly incorporated into the management framework if a precautionary approach is to be adopted.

Acknowledgements. We thank Jane Lancaster for unpublished data on the survival of discarded dabs, Tom Mercer, Kirsty Harwood, John Hall for the collection and analysis of the contemporary stomachs, the master and crew of FV "Transcend' and all those involved in the collection of the $1950 \mathrm{~s}$ data set. The authors would especially like to acknowledge John Hall for providing us with an endless source of frustration. The European Commission funded this work under study contract number $94 / 77$ to C.L.J.F and S.J.H.

\section{LITERATURE CITED}

Bishop YMM, Fienberg SE, Holland PW (1975) Discrete multivariate analysis: theory and practice. MIT Press, Cambridge, MA

Clark RB, Frid CLJ, Attrill M (1997) Marine pollution. Oxford University Press, Oxford

Creutzberg F, Duineveld GCA (1986) The role of the lesser weaver, Trachinus vipera and the dab, Limanda limanda in the benthic system of the southern North Sea. ICES CM 1986/L $4: 1-10$

DeClerke R, Torreele E (1988) Feeding habits of the common dab (Limanda limanda L.) in the southern North Sea. ICES CM1988/G:26

de Groot SJ, Lindeboom, HJ (1994) Environmental impact of bottom gears on benthic fauna in relation to natural

Editorial responsibility: John Gray (Contributing Editor), Oslo, Norway resources management and protection of the North Sea. Reports of the Netherlands Institute for Sea Research, Texel

Efron B, Tibshironi R (1986) Bootstrap methods for standard error, confidence intervals and other measures of statistical accuracy. Stat Sci 1:54-77

Greenstreet SPR (1996) Estimating the daily consumption of production by fish in the North Sea in each quarter of the year. Scottish Fisheries Research Report 55

Hall SJ, Raffaelli D, Basford DJ, Robertson MR, Fryer R (1990) The feeding relationships of the larger fish species in a Scottish sea loch. J Fish Biol 37:775--791

Hickel WJ, Mangelsdorf P, Berg J (1993) The human impact in the German Bight: eutrophication during three decades (1962-1991). Helgol Wiss Meeresunters 47:243-263

Jennings $S_{1}$ Kaiser $M J$ (1998) The effects of fishing on marine ecosystems. Adv Mar Biol 34:201-352

Josetson AB, Jensen JN, Aertebjerg G (1993) The benthos community structure in the late 1970 s and early $1980 \mathrm{~s}-\mathrm{a}$ result of a major food pulse? J Exp Mar Biol Ecol 172: $31-4.5$

Kaiser MJ, Spencer BE (1996) Behavioural responses of scavengers to beam trawl disturbance. In: Greenstreet SPR, Tasker ML (eds) Aquatic predators and their prey. Blackwell, Oxford, p 116-123

Knust R (1986) Food selection of dab (Limanda limanda (L.)): diel and seasonal changes. International Council for the Exploration of the Sea CM 1986/G:63

Knust R (1996) Food ecology of North Sea dab (Limanda limanda). 1 Seasonal changes in food uptake and condition in the German Bight and on Dogger Bank. Arch Fish Mar Res 44:1-12

Krebs CJ (1989) Ecological methodology. Harper and Row, New York

Kroncke I (1990) Macrofauna standing stock of the Dogger Bank. A comparison: II. 1951-1952 versus 1985-1987. Are changes in the community of the northeastern part of the Dogger Bank due to environmental changes? Neth J Sea Res 25:189-198

Miller RG (1974) The jackknife - a review. Biometrika 61 $1-15$

Pearson TH, Mannvik HP (1998) Long-term changes in the diversity and faunal structure of benthic communities in the northern North Sea: natural variability or induced instability? Hydrobiologia 376:31.7-329

Reise K (1982) Long-term changes in the macrobenthic invertebrate fauna of the Wadden Sea: are polychaetes about to take over? Neth J Sea Res 16:29-36

Thrush SF, Hewitt JE, Cummings VJ, Dayton PK, Cryer M, Turner SJ, Funnell GA, Budd RG, Milburn CJ, Wilkinson MR (1998) Disturbance of the marine benthic habitat by commercial fishing: impacts at the scale of the fishery. Ecol App 8:866-879

Tuck ID, Hall SJ, Robertson MR, Armstrong $E_{1}$ Basford DJ (1998) Effects of physical trawling disturbance in a previously unfished sheltered Scottish. sealoch. Mar Ecol Prog Ser 162:227-242

Submitted: November 23, 1998; Accepted: March 5, 1999 Proofs received from author(s): July 19, 1999 